University of Nebraska - Lincoln

DigitalCommons@University of Nebraska - Lincoln

Evaluation of Different Insecticides and Fabric Types for Development of Treated Targets for Stable Fly (Diptera: Muscidae) Control

Jerome Hogsette

United States Department of Agriculture-ARS-Center for Medical, Jerry.Hogsette@ars.usda.gov

Alyce Nalli

USDA-ARS

Lane Foil

USDA-ARS

Follow this and additional works at: https://digitalcommons.unl.edu/usdaarsfacpub

Part of the Agricultural Science Commons

Hogsette, Jerome; Nalli, Alyce; and Foil, Lane, "Evaluation of Different Insecticides and Fabric Types for Development of Treated Targets for Stable Fly (Diptera: Muscidae) Control" (2008). Publications from USDA-ARS / UNL Faculty. 1016.

https://digitalcommons.unl.edu/usdaarsfacpub/1016

This Article is brought to you for free and open access by the U.S. Department of Agriculture: Agricultural Research Service, Lincoln, Nebraska at DigitalCommons@University of Nebraska - Lincoln. It has been accepted for inclusion in Publications from USDA-ARS / UNL Faculty by an authorized administrator of DigitalCommons@University of Nebraska - Lincoln. 


\title{
Evaluation of Different Insecticides and Fabric Types for Development of Treated Targets for Stable Fly (Diptera: Muscidae) Control
}

\author{
JEROME A. HOGSETTE, ${ }^{1}$ ALYCE NALLI, AND LANE D. FOIL ${ }^{2}$
}

USDA-ARS, Center for Medical, Agricultural and Veterinary Entomology, 1600 S. W. 23rd Drive, Gainesville, FL 32608

J. Econ. Entomol. 101(3): 1034-1038 (2008)

\begin{abstract}
Stable fly, Stomoxys calcitrans (L.) (Diptera: Muscidae), once only a pest of pastured cattle, has become a serious pest of range cattle in the United States. Because of the difficulties associated with stable fly management under range conditions, a pesticide-impregnated cloth target is being developed as a management tool. We conducted studies to determine the influence of weather, time, fabric type, insecticide type, and insecticide concentration on the mortality of stable flies from a susceptible laboratory colony exposed for $30 \mathrm{~s}$ to treated cloth targets. We found that $100 \%$ of the flies exposed to trigger (Trigger-Royal Box, $65 \%$ polyester and $35 \%$ cotton) fabric targets that were treated with $0.1 \% \lambda$-cyhalothrin or $0.1 \%$-cypermethrin and weathered outdoors in Gainesville, FL., for up to $3 \mathrm{mo}$, were dead within $20 \mathrm{~min}$ after a 30-s exposure. The results of this study support the concept that treated targets can be developed for integration into stable fly control programs.
\end{abstract}

KEY WORDS fly control, biting flies, cloth targets, livestock pests

The stable fly, Stomoxys calcitrans (L.) (Diptera: Muscidae), is a major pest of livestock in many countries, including the United States (Kunz et al. 1991, Hogsette and Farkas 2000). Adults are persistent in their attempts to obtain a bloodmeal and populations frequently exceed the accepted economic damage thresholds (Campbell et al. 1987). Stable flies also are considered to be mechanical vectors of many livestock disease agents worldwide (Foil 1989, Hogsette and Farkas 2000).

Stable flies develop around and feed on livestock confined in feedlots, small pastures, or paddocks where larval habitats are numerous (Broce et al. 2005). Before the 1980s, livestock in large rangeland pastures typical of the western United States were seemingly exempt from predation by stable flies (Hogsette 1999). In the 1980s, many producers who fed hay to pastured livestock switched from the traditional small square hay bales to the large, round hay bales. Since that time, the stable fly has emerged as a major problem for pastured cattle in the United States (Campbell et al. 2001, Broce et al. 2005). The increase in adult populations seems to be a result of the presence of larval habitats produced by rolled hay residues that have been mixed with manure and urine and trampled by the animals as they feed (Hogsette et al. 1987). Immature stable fly populations of 28,000 per $\mathrm{m}^{2}$ have been found in these habitats (Patterson and Morgan 1986).

\footnotetext{
${ }^{1}$ Corresponding author, e-mail: jhogsette@gainesville.usda.ufl.edu.

${ }^{2}$ Department of Entomology, Louisiana State University Agricultural Center, Baton Rouge, LA 70803.
}

Currently, there are no effective control measures available for stable fly larvae or adults in pastured livestock situations (Foil and Hogsette, 1994, Broce et al. 2005). Application of insecticides to pastured livestock is not practical because residual activity is short lived and stable flies spend the majority of their adult lives off the host (Farkas and Hogsette 2000). Toxicant devices made from fiberglass stable fly traps (Williams 1973) treated directly (Meifert et al. 1978) or indirectly (Hogsette and Ruff 1996) with pesticides were developed for stable fly management, but these devices have never been widely used.

Targets made from inexpensive blue and black cotton fabric panels were found to be highly attractive to testse flies (Glossina spp.) in Africa (Vale 1993). Selected fabrics impregnated with deltamethrin were shown to kill tsetse flies in the field for $>4$ mo (Torr et al. 1992). Stable flies also are attracted to blue/black fabric combinations (Mihok et al. 1995, Mihok 2002, Foil and Hogsette 2004). Furthermore, stable flies have been shown to land preferentially on blue/black fabric targets and remain on the targets for at least $30 \mathrm{~s}$ (Foil and Younger 2006).

The purpose of this study was to determine the effects of weather, time, and fabric types on the residual activities of selected formulations and concentrations of insecticides that might be used to treat cloth targets for stable fly control. We chose a 90 -d weathering period because this is the approximate length of the stable fly season in many parts of the United States; and a 30-s exposure period based on the fieldwork of Foil and Younger (2006). 


\section{Materials and Methods}

Fabrics. Four types of blue fabric were tested: trigger (Trigger-Royal Box, $65 \%$ polyester and $35 \%$ cotton, Galey and Lord Inc., New York, NY), canvas (Royal cotton custom canvas, $100 \%$ cotton, Galey and Lord Inc.), t-shot (Blueprint T-shot, $65 \%$ polyester and $35 \%$ cotton, Spring Mills Inc., New York, NY), and polyester (100\% polyester, Royal Blue No. 11, Vestergaard Frandsen, Denmark).

Panels $(0.5$ by $1 \mathrm{~m})$ were cut from each fabric type. There were six panels for each insecticide/control treatment group (three for weathering outside, three for weathering inside) for a total of 102. The panels were soaked until saturation in insecticide solutions or water as a control and then hung up to dry. Fabric panels were treated, dried, and packaged in Baton Rouge, LA, and then they were shipped to the USDAARS, CMAVE laboratory in Gainesville, FL, for testing.

Insecticides. Five formulations of four insecticides were tested: 0.1\% cypermethrin (Ammo 2.5 EC 29.9\%, batch PL030-0041, FMC, Princeton, NJ); 0.1\% permethrin (Pounce 3.2 EC 38.4\%, batch PL00-0097, FMC, Princeton, NJ); $0.1 \%$ $\zeta$-cypermethrin (Mustang 1.5 EC 18.1\%, batch PL01-0068, FMC, Princeton, NJ); $0.1,0.5$, and $1 \% \lambda$-cyhalothrin (Demand CS 9.7\%, batch XAG1801, Zeneca, Wilmington, DE); and $0.1 \%$ $\zeta$-cypermethrin (Mustang EW 17.1\%, batch PL020341; FMC, Philadelphia, PA).

Comparisons. Three general comparisons were made between a treatment (fabric type, insecticide formulation, or insecticide concentration), weathering conditions (inside or outside), and exposure time (days).

Fabric Comparison. Four fabric types treated with $0.1 \% \lambda$-cyhalothrin were compared with determine the mean time required to produce $100 \%$ mortality in stable flies exposed to each fabric type for $30 \mathrm{~s}$. There was a corresponding untreated control for each fabric type.

Insecticide Comparison. The five formulations of four insecticides $(0.1 \%[\mathrm{AI}])$ were compared on trigger fabric to determine the mean time required to produce $100 \%$ mortality in stable flies exposed to treated fabric for $30 \mathrm{~s}$. An untreated trigger control fabric was included in this comparison.

Insecticide Concentration Comparison. Three concentrations of $\lambda$-cyhalothrin $(0.1,0.5$, and $1.0 \%)$ were compared on trigger fabric to determine the mean time required to produce $100 \%$ mortality in stable flies exposed to treated fabrics for $30 \mathrm{~s}$. An untreated trigger control fabric was included in this comparison.

Weathering and Sample Collection. The two threepanel sets of each insecticide/control treatment fabrics were weathered for $3 \mathrm{mo}$, from 15 July 2003 to 15 October 2003. One set was hung in a shed with closed sides and a roof, but open ends. Fabrics were out of the sun and rain, but otherwise exposed to ambient conditions. The other set of fabrics was hung outside in full sun. Samples $(\approx 10$ by $10 \mathrm{~cm}$ ) were cut from each cloth panel on 15 July (day 0), 15 August, 15 September, and
15 October 2003, returned to the laboratory and subjected to the stable fly bioassay. Samples were placed between sheets of waxed paper during transport to prevent contamination. Cumulative rainfall and minimum/maximum temperature were recorded during the 3-mo weathering periods.

Test Insects. Adult male and female stable flies (3-5 d old) from the USDA Gainesville colony were used for all tests; basic rearing techniques were similar to those described by Hogsette (1992). Adults were maintained in colony cages ( 46 by 38 by $38 \mathrm{~cm}$ in height), held under standard laboratory conditions $\left(26 \pm 2{ }^{\circ} \mathrm{C}, 60 \pm 5 \% \mathrm{RH}\right.$, and a photoperiod of $12: 12$ [L:D] h), and given ad libitum access to citrated bovine blood.

Stable Fly Bioassay. To allow introduction of flies, 1-cm-diameter holes were burned into the center of the lids of 100- by 20 -mm plastic petri dishes. To begin a bioassay, a fabric sample was placed across the bottom of a petri dish. Because the fabric sample was square, the corners of the sample extended across the perimeter of the round petri dish. When the lid of the dish was replaced, it clamped the corners of the fabric causing the fabric to be suspended $\approx 5 \mathrm{~mm}$ beneath the lid. This ensured that flies placed between the fabric sample and the lid of the petri dish would be in tarsal contact with the fabric during the entire exposure period. There were three cloth samples for each insecticide/control treatment. Stable flies were removed from a colony cage with a battery-powered aspirator, and $\approx 15$ flies were blown into each petri dish through the hole in the lid. Each hole was closed immediately with a dry cotton plug. After a 30-s exposure, the cloth was removed, carefully and quickly, and the flies were retained in the dish. Approximately $1 \mathrm{~h}$ after the cloth samples were removed, the dry cotton plugs from petri dishes containing live flies were replaced with cotton plugs saturated with an aqueous $10 \%$ sucrose solution. The sucrose would provide sustenance to the flies and minimize mortality from causes other than the pesticides. The time until $100 \%$ of the flies were dead was recorded by constant observation for the first hour and at 15-min intervals for the next $4 \mathrm{~h}$. The criterion of death was complete cessation of movement. Dead flies were observed after $24 \mathrm{~h}$ to check for possible recovery.

Design and Statistical Analysis. There were 12 control groups (six inside and six outside) and 24 treatment groups (12 inside and 12 outside) in this study. Thus, there were 36 groups of 15 stable flies $(\Sigma=540$ flies) tested at each of the four sampling dates. Analyses were conducted to determine the influence of fabric type, insecticide type, insecticide concentration, exposure (full sun or covered), weather (mean temperature and precipitation), and length of exposure $(0,1,2$, or $3 \mathrm{mo})$ on the mortality of stable flies. Data were analyzed in a completely randomized design by using one of the following models: mortality $=$ fabric type, insecticide type, or insecticide concentration + exposure + temperature + rain + exposure time (PROC GLM, SAS Institute 2003). Means were separated with Duncan's multiple range test. Unless 
Table 1. Mean \pm SEM time (minutes) required by four selected blue fabrics treated with a $0.1 \%$ concentration of $\lambda$-cyhalothrin CS to produce $100 \%$ mortality in stable flies exposed for $30 \mathrm{~s}$ in a laboratory assay $(n=3)$

\begin{tabular}{|c|c|c|c|c|}
\hline \multirow{2}{*}{ Exposure time $(\mathrm{d})$} & \multicolumn{4}{|c|}{ Fabric $^{a}$} \\
\hline & Canvas & Trigger & T-Shot & Poly \\
\hline \multicolumn{5}{|l|}{ Weathered inside } \\
\hline 0 & $5.9 \pm 0.2 \mathrm{Bx}$ & $11.7 \pm 0.6 \mathrm{Ax}$ & $9.7 \pm 1.0 \mathrm{Ax}$ & $4.4 \pm 1.0 \mathrm{Bx}$ \\
\hline 30 & $10.3 \pm 1.6 \mathrm{Ay}$ & $9.5 \pm 0.6 \mathrm{Ax}$ & $9.3 \pm 0.6 \mathrm{Ax}$ & $4.2 \pm 0.1 \mathrm{Bx}$ \\
\hline 60 & $9.8 \pm 1.3 \mathrm{ABxy}$ & $11.6 \pm 1.7 \mathrm{Ax}$ & $10.9 \pm 0.4 \mathrm{Axy}$ & $6.2 \pm 0.8 \mathrm{Bx}$ \\
\hline 90 & $7.9 \pm 1.2 \mathrm{Bxy}$ & $12.6 \pm 1.6 \mathrm{Ax}$ & $12.4 \pm 0.6 \mathrm{Ay}$ & $4.9 \pm 0.8 \mathrm{Bx}$ \\
\hline \multicolumn{5}{|l|}{ Weathered outside } \\
\hline 0 & $6.9 \pm 0.5 \mathrm{BCx}$ & $8.0 \pm 0.9 \mathrm{ABx}$ & $9.9 \pm 0.4 \mathrm{Ax}$ & $5.6 \pm 0.8 \mathrm{Cx}$ \\
\hline 30 & $516.4 \pm 461.8 \mathrm{Axy}$ & $13.6 \pm 1.0 \mathrm{Axy}$ & $24.4 \pm 2.4 \mathrm{Ax}$ & $11.2 \pm 0.0 \mathrm{Ax}$ \\
\hline 60 & $1006.4 \pm 433.6$ Axy & $21.4 \pm 3.7 \mathrm{By}$ & $37.2 \pm 4.0 \mathrm{Bx}$ & $28.0 \pm 4.9 \mathrm{By}$ \\
\hline 90 & N.A. & $20.1 \pm 2.4 \mathrm{By}$ & $506.5 \pm 466.8 \mathrm{Ax}$ & $440.0 \pm 0.0 \mathrm{Az}$ \\
\hline
\end{tabular}

Mean mortality times by weathering regimen in columns (lowercase) and by weathering regimen and exposure time in rows (uppercase) followed by the same letter are not significantly different $(P \leq 0.05$; Duncan's multiple range test [SAS Institute 2003]).

${ }^{a}$ Canvas, $100 \%$ cotton canvas-Blue; Trigger, Trigger-Royal Box, $65 \%$ polyester, $35 \%$ cotton; T-Shot, cotton T-Shot-Blue; and Poly, $100 \%$ polyester-Royal Blue (No. 11). N.A., 100\% mortality interval $\geq 24 \mathrm{~h}$.

otherwise stated, $P \leq 0.05$ (SAS Institute 2003). If the time required to produce $100 \%$ mortality was $\geq 24 \mathrm{~h}$ (1,440 min) after the cloth was removed from a petri dish, this was considered unsatisfactory for practical purposes in the field, and values in this range were not included in the analyses.

\section{Results}

Cumulative rainfall and average temperatures were $27.61,10.85$, and $9.53 \mathrm{~cm}$ and $31.1,29.6$, and $25.7^{\circ} \mathrm{C}$, respectively, during the three $30-\mathrm{d}$ weathering periods. Times required to produce $100 \%$ mortality were not affected by temperature or rainfall, and these variables were removed from the models. In laboratory testing, no mortality was recorded in any of the 12 different control groups at $24 \mathrm{~h}$ after treatment. There was no recovery of any flies considered to be dead from any group.

Fabric Comparison. In the main effects analysis when the four fabric types were treated with a $0.1 \%$ concentration of $\lambda$-cyhalothrin, fabric type, exposure time (days), and exposure (full sun or covered) were all significant $(F=7.64 ; \mathrm{df}=6,71 ; P<0.0001)$. Day
0 comparisons of times required to produce $100 \%$ mortality in flies exposed to the same fabric, weathered inside and outside, were similar (Table 1). At day 90 for fabrics weathered inside, times required to produce $100 \%$ mortally were significantly shorter for canvas and polyester than for trigger and t-shot (Table 1). However for fabrics weathered for $90 \mathrm{~d}$ outside, trigger produced $100 \%$ mortality in a significantly shorter time than t-shot and polyester. Canvas weathered outside failed completely after the 60-d bioassay (Table 1).

Insecticide Comparison. In the main effects analysis when trigger fabric was treated with $0.1 \%$ concentrations of five insecticide types, insecticide type, exposure time (days), and exposure (full sun or covered) were all significant $(F=10.82 ; \mathrm{df}=8,119 ; P<0.0001)$. Day 0 comparisons of times required to produce $100 \%$ mortality in flies exposed to trigger fabric containing the same insecticide, weathered inside and outside, were similar, with the exception of fabric treated with permethrin EC (Table 2). On day 90, trigger fabric treated with $\zeta$-cypermethrin EW and weathered inside required a significantly greater time to produce $100 \%$ mortality than trigger fabric weathered similarly but treated with $\lambda$-cyhalothrin CS or cypermethrin EC

Table 2. Mean \pm SEM time (minutes) required by $0.1 \%$ concentrations of five pyrethroid pesticide formulations in trigger fabric to produce $100 \%$ mortality in stable flies exposed for $30 \mathrm{~s}$ in a laboratory assay $(n=3)$

\begin{tabular}{|c|c|c|c|c|c|}
\hline \multirow{2}{*}{ Exposure time (d) } & \multicolumn{5}{|c|}{ Insecticide $^{a}$} \\
\hline & CyperEC & L-CyCS & PermEC & ZetacyEC & ZetacyEW \\
\hline \multicolumn{6}{|l|}{ Weathered inside } \\
\hline 0 & $16.4 \pm 1.8 \mathrm{ABx}$ & $11.7 \pm 0.5 \mathrm{Bx}$ & $19.4 \pm 0.4 \mathrm{Ax}$ & $12.5 \pm 0.9 \mathrm{ABx}$ & $17.3 \pm 4.5 \mathrm{ABx}$ \\
\hline 30 & $21.4 \pm 6.7 \mathrm{ABx}$ & $14.1 \pm 2.1 \mathrm{Bx}$ & $30.2 \pm 5.6 \mathrm{Ay}$ & $19.6 \pm 1.6 \mathrm{ABxy}$ & $16.4 \pm 1.0 \mathrm{ABx}$ \\
\hline 60 & $19.3 \pm 3.4 \mathrm{ABx}$ & $13.0 \pm 0.8 \mathrm{Bx}$ & $20.5 \pm 0.2 \mathrm{Ax}$ & $19.5 \pm 2.9 \mathrm{ABxy}$ & $20.0 \pm 1.2 \mathrm{ABx}$ \\
\hline 90 & $23.3 \pm 3.1 \mathrm{Bx}$ & $26.7 \pm 6.6 \mathrm{By}$ & $34.3 \pm 0.6 \mathrm{ABy}$ & $28.6 \pm 4.9 \mathrm{ABy}$ & $40.8 \pm 1.2 \mathrm{Ay}$ \\
\hline \multicolumn{6}{|l|}{ Weathered outside } \\
\hline 0 & $21.9 \pm 5.2 \mathrm{Ax}$ & $11.3 \pm 1.0 \mathrm{Ax}$ & $80.9 \pm 47.0 \mathrm{Ax}$ & $15.1 \pm 0.8 \mathrm{Ax}$ & $16.3 \pm 1.7 \mathrm{Ax}$ \\
\hline 30 & $506.7 \pm 466.7 \mathrm{Ax}$ & $19.3 \pm 1.6 \mathrm{Ax}$ & $980.4 \pm 459.6 \mathrm{Ay}$ & $22.2 \pm 2.8 \mathrm{Axy}$ & $24.8 \pm 2.7 \mathrm{Ax}$ \\
\hline 60 & $110.8 \pm 13.5 \mathrm{Bx}$ & $31.7 \pm 9.8 \mathrm{Dx}$ & N.A. & $60.8 \pm 24.8 \mathrm{CDy}$ & $82.8 \pm 15.3 \mathrm{BCy}$ \\
\hline 90 & N.A. & $969.8 \pm 470.2 \mathrm{Ay}$ & N.A. & $18.2 \pm 2.1 \mathrm{Bx}$ & N.A. \\
\hline
\end{tabular}

Mean mortality times by weathering regimen in columns (lowercase) and by weathering regimen and exposure time in rows (uppercase) followed by the same letter are not significantly different $(P \leq 0.05$; Duncan's multiple range test [SAS Institute 2003]).

${ }^{a}$ CyperEC, cypermethrin EC; L-CyCS, $\lambda$-cyhalothrin CS; PermEC, permethrin EC; ZetacyEC, $\zeta$-cypermethrin EC; ZetacyEW, $\zeta$-cypermethrin EW. N.A., $100 \%$ mortality interval $\geq 24 \mathrm{~h}$. 
Table 3. Mean $\pm \mathrm{SEM}$ time (minutes) required by trigger fabric treated with three concentrations of $\boldsymbol{\lambda}$-cyhalothrin CS to produce $100 \%$ mortality in stable flies exposed for $30 \mathrm{~s}$ in a laboratory assay $(n=3)$

\begin{tabular}{cccc}
\hline \hline & \multicolumn{3}{c}{ Concn. (\%) } \\
\cline { 2 - 4 } Exposure time $(\mathrm{d})$ & 0.1 & 0.5 & 1.0 \\
\cline { 2 - 4 } & & & \\
Weathered inside & $10.2 \pm 0.7 \mathrm{Ax}$ & $9.0 \pm 0.4 \mathrm{Ay}$ & $4.4 \pm 0.8 \mathrm{Bx}$ \\
0 & $14.4 \pm 0.8 \mathrm{Ay}$ & $5.8 \pm 0.2 \mathrm{Bx}$ & $5.8 \pm 0.6 \mathrm{~B}$ \\
30 & $14.1 \pm 1.5 \mathrm{Axy}$ & $8.4 \pm 1.0 \mathrm{By}$ & $8.4 \pm 0.9 \mathrm{By}$ \\
60 & $13.7 \pm 1.2 \mathrm{Axy}$ & $10.0 \pm 1.0 \mathrm{By}$ & $12.4 \pm 0.8 \mathrm{ABz}$ \\
90 & & & \\
Weathered outside & $8.1 \pm 1.6 \mathrm{Ax}$ & $6.5 \pm 0.1 \mathrm{ABx}$ & $4.2 \pm 0.2 \mathrm{Bx}$ \\
0 & $16.4 \pm 1.0 \mathrm{Ayz}$ & $11.6 \pm 0.3 \mathrm{By}$ & $8.9 \pm 0.5 \mathrm{Cx}$ \\
30 & $18.1 \pm 2.0 \mathrm{Ayz}$ & $17.3 \pm 1.1 \mathrm{Az}$ & $17.1 \pm 1.0 \mathrm{Ay}$ \\
60 & $21.9 \pm 1.0 \mathrm{Az}$ & $20.2 \pm 2.1 \mathrm{Az}$ & $17.0 \pm 2.7 \mathrm{Ay}$ \\
90 & & & \\
\hline
\end{tabular}

Mean mortality times by weathering regimen in columns (lowercase) and by weathering regimen and exposure time in rows (uppercase) followed by the same letter are not significantly different $(P \leq 0.05$; Duncan's multiple range test; [SAS Institute 2003]).

(Table 2). However, there were no significant differences at day 90 between trigger fabrics weathered inside and treated with cypermethrin EC, $\lambda$-cyhalothrin CS, permethrin EC, or $\zeta$-cypermethrin EC ( Table 2). When insecticide-treated trigger fabrics were weathered outside, the $\zeta$-cypermethrin EC treatment produced $100 \%$ mortality on day 90 in significantly less time than the other insecticides tested. However, permethrin EC failed at the 60-d bioassay and cypermethrin EC and $\zeta$-cypermethrin EW failed at the 90-d bioassay. The $\lambda$-cyhalothrin-treated trigger fabric weathered outside required significantly more time to produce $100 \%$ mortality at $90 \mathrm{~d}$ than at $60 \mathrm{~d}$ (Table 2 ).

Insecticide Concentration Comparison. In the main effects analysis when trigger fabric was treated with three concentrations of $\lambda$-cyhalothrin CS, insecticide concentration, exposure time (days), and exposure (full sun or covered) were all significant $(F=26.61$; $\mathrm{df}=6,71 ; P<0.0001)$. Day 0 comparisons of times required to produce $100 \%$ mortality in flies exposed to trigger fabric containing the same insecticide concentration, weathered inside and outside, were similar (Table 3). At day 90 with fabrics weathered inside, numerical time differences required to produce $100 \%$ mortality by the three insecticide concentrations were slight (Table 3). When fabrics were weathered outside, times required by the three insecticide concentrations to produce $100 \%$ mortality at day 90 were not significantly different; however significant time differences did exist between the first and last exposure periods for each insecticide concentration (Table 3).

\section{Discussion}

Traps or treated targets for the control of stable fly populations have shown promise in several studies (Hogsette et al. 1987; Rugg, 1982; Hogsette and Ruff 1996). In particular, Meifert et al. (1978) used permethrin-treated alsynite targets at a rate of one per five head of cattle at two sites in Florida, and estimated that the units removed $>30 \%$ of the stable fly popu- lation during their study. Our results when joined with those of Foil and Younger (2006) seem to be more promising than those of previous studies, where pyrethroids (permethrin) were combined with alsynite fiberglass panels or cylinders (Meifert et al. 1978, Hogsette and Ruff 1996). Foil and Younger (2006) conducted electric grid studies and found that half blue and half black $1-\mathrm{m}^{2}$ UK trigger targets attracted a 6.1-fold higher number of stable flies than alsynite cylinder traps. Therefore, UK trigger targets impregnated with insecticides could be a potential tool for stable fly control programs.

In our evaluation of fabric types, we determined that weathering outside in full sun adversely affected pesticide residue longevity in all fabrics tested (Table 1). This is an important finding because these targets are designed to be used primarily outside. Pesticide residues in trigger, the fabric of choice in previous studies (Foil and Younger 2006), were least affected. The candidate insecticide for these evaluations, $0.1 \%$ $\lambda$-cyhalothrin CS, performed well in trigger fabric when weathered inside or outside (Table 1). After a 90-d exposure period outside, the time required to produce $100 \%$ mortality was $20 \mathrm{~min}$, or just 1.67 times longer than trigger fabric weathered inside for the same $90-d$ period.

When trigger fabric was treated with five different insecticides, including $\lambda$-cyhalothrin CS, all formulated at $0.1 \%$, results were more variable. Only two of the insecticides weathered outside, $\lambda$-cyhalothrin and $\zeta$-cypermethrin, produced $100 \%$ mortality in $<24 \mathrm{~h}$ (Table 2). The $\lambda$-cyhalothrin did not perform as expected based on the results shown in Table 1, possibly because of an error in the evaluation process. However when juxtaposed, the 90-d evaluation values for $0.1 \% \lambda$-cyhalothrin from Tables 1 and 3 , and $0.1 \%$ $\zeta$-cypermethrin from Table 2 , all weathered simultaneously outdoors, are numerically similar. When trigger fabric was treated with three concentrations of $\lambda$-cyhalothrin and weathered outside for $90 \mathrm{~d}$, there were no significant differences between times required to produce $100 \%$ mortality. Thus, there is no need to use a $\lambda$-cyhalothrin concentration higher than $0.1 \%$ for the targets.

Results indicate that either $\lambda$-cyhalothrin CS or $\zeta$-cypermethrin EC, formulated at $0.1 \%$, would be suitable for use with targets made from trigger fabric. However, $\lambda$-cyhalothrin CS was the final choice at present because this pesticide is labeled for application to cloth for insect control. Our results support the concept that treated targets similar to those used for tsetse control could be used for stable fly control.

\section{Acknowledgments}

We thank Cole Younger, Louisiana State University, and Tracey Tam, University of Florida, for technical assistance. L.D.F. thanks Glyn Vale and Steve Torr for sharing knowledge and techniques for development of targets. This study was supported in part by a Southern Regional IPM grant. 


\section{References Cited}

Broce, A. B., J. A. Hogsette, and S. Paisley. 2005. Winter feeding sites of hay in round bales as major developmental sites of Stomoxys calcitrans (Diptera: Muscidae) in pastures in spring and summer. J. Econ. Entomol. 98: 2307-2312.

Campbell, J. B., I. L. Berry, D. J. Boxler, R. L. Davis, D. C. Clanton, and G. H. Deutscher. 1987. Effects of stable flies (Diptera: Muscidae) on weight gain and feed efficiency of feedlot cattle. J. Econ. Entomol. 80: 177-119.

Campbell, J. B., S. R. Skoda, D. R. Berkebile, D. J. Boxler, G. D. Thomas, D. C. Adams, and R. Davis. 2001. Effects of stable flies (Diptera: Muscidae) on weight gain of grazing yearling cattle. J. Econ. Entomol. 94: 780-783.

Farkas, R., and J. A. Hogsette. 2000. Control possibilities of filth-breeding flies in livestock and poultry production, pp. 889-904. In L. Papp and B. Darvas [eds.], Contributions to a manual of Palearctic Diptera, vol. 1. General and applied dipterology. Science Herald, Budapest, Hungary.

Foil, L. D. 1989. Tabanids as vectors of disease agents. Parasitol. Today 5: 88-96.

Foil, L. D., and J. A. Hogsette. 1994. Biology and control of tabanids, stable flies, and horn flies. Rev. Sci. Tech. Off. Int. Epiz. 13: 1125-1158.

Foil, L. D., and J. A. Hogsette. 2004. Treated targets for stable fly control, p. 173. In Proceedings of the XXII International Congress of Entomology, 15-21 August 2004, Brisbane, Australia. Carillon Conference Management Pty. Limited, Brisbane, Australia.

Foil, L. D., and C. D. Younger. 2006. Development of treated targets for controlling stable flies (Diptera: Muscidae). Vet. Parasitol. 137: 311-315.

Hogsette, J. A. 1992. New diets for production of house flies and stable flies (Diptera: Muscidae) in the laboratory. J. Econ. Entomol. 85: 2291-2294.

Hogsette, J. A. 1999. Management of ectoparasites with biological control organisms. Int. J. Parasitol. 29: 147-151.

Hogsette, J. A., and J. P. Ruff. 1996. Permethrin-impregnated yarn: longevity of efficacy and potential use on cylindrical fiberglass stable fly (Diptera: Muscidae) traps. J. Econ. Entomol. 89: 1521-1525.
Hogsette, J. A., and R. Farkas. 2000. Secretophagous and hematophagous higher Diptera, pp. 769-792. In L. Papp and B. Darvas [eds.], Contributions to a manual of Palearctic Diptera, vol. 1. General and applied dipterology. Science Herald, Budapest, Hungary.

Hogsette, J. A., J. P. Ruff, and C. J. Jones. 1987. Stable fly biology and control in northwest Florida. J. Agric. Entomol. 4: 1-11.

Kunz, S. E., K. D. Murrel, G. Lambert, L. F. James, and C. E. Terrill. 1991. Estimated losses of livestock to pests, pp. 69-98. In D. Pimentel [ed.], CRC handbook of pest management in agriculture, vol. I. CRC, Boca Raton, FL.

Meifert, D. W., R. S. Patterson, T. Whitfield, G. C. LaBrecque, and D. E. Weidhaas. 1978. Unique attractant-toxicant system to control stable fly populations. J. Econ. Entomol. 71: 290-292.

Mihok, S. 2002. The development of a multipurpose trap (the Nzi) for tsetse and other biting flies. Bull. Entomol. Res. 92: 385- 403.

Mihok, S., E. K. Kang'ethe, and G. K. Kamau. 1995. Trials of traps and attractants for Stomoxys spp. (Diptera: Muscidae). J. Med. Entomol. 32: 283-289.

Patterson, R. S., and P. B. Morgan. 1986. Factors affecting the use of an IPM scheme at poultry installations in a semitropical climate, pp. 101-107. In R. S. Patterson and D. A. Rutz [eds.], Biological control of muscoid flies. Entomol. Soc. Am. Misc. Publ. No. 61. Lanham, MD.

Rugg, D. 1982. Effectiveness of Williams traps in reducing the numbers of stable flies (Diptera: Muscidae). J. Econ. Entomol. 75: 857-859.

Torr, S. J., M.T.P. Holloway, and G. A. Vale. 1992. Improved persistence of insecticide deposits on targets for controlling Glossina pallidipes (Diptera: Glossinidae). Bull. Entomol. Res. 82: 525-533.

SAS Institute. 2003. SAS version 9.1 for Windows. SAS Institute, Cary, NC.

Vale, G. A. 1993. Development of baits for tsetse flies (Diptera: Glossinidae) in Zimbabwe. J. Med. Entomol. 30: 831-842.

Williams, D. F. 1973. Sticky traps for sampling populations of Stomoxys calcitrans. J. Econ. Entomol. 66: 1279-1280.

Received 22 December 2006; accepted 20 October 2007. 